Marc-André Simard

Université de Montréal, Montréal, Québec, Canada

Toluwase Asubiaro

Western University, London, Ontario, Canada

Philippe Mongeon

Dalhousie University, Halifax, Nova Scotia, Canada

\title{
The burden of article processing charges on Canadian universities (Paper)
}

\begin{abstract}
The question about the cost of access to scholarly resources is usually answered by focusing on subscription cost. This study highlights the article processing charges (APCs) paid by Canada's research institution as an additional scholarly resource. Unpaywall database was queried with the DOIs of CARL member universities' publication indexed in the Web of Science. We find that while Open Access should in principle reduce the cost of access to scholarly literature, we are rather in a situation where both the cost of access and the cost of publishing are increasing simultaneously.
\end{abstract}

\section{Introduction}

\section{Serial Crisis}

In the late 1960s and early 1970s, commercial publishers began acquiring university presses and scientific societies under the guise of taking off the burden of managing the business side of scientific journals while the scientific societies were promised royalties in return: an appealing offer for societies that were sometimes running scientific publishing at loss (Edwards \& Shulenburger, 2003). These commercial publishers also provided a more efficient knowledge dissemination channel than what the scientific societies were able to achieve at the time (Brock, 1980). The downside of the commercialization of scholarly publishing has been a quest for profits which ultimately led to increasing subscription costs for academic libraries, a pattern that, in combination with the growth of scientific output and journals, led libraries into a "serials crisis". This crisis caused by the hyperinflation of journal prices well above national inflation averages and above library budget increases made the status quo difficult to maintain for universities (Suber, 2012). Just about fifteen years after the introduction of the journal bundles (the "Big Deal") as a panacea to this problem Frazier (2001), the continuous price increase of these bundles has led libraries back to square one.

In Canada, the price of journal subscriptions has risen by an estimated $402 \%$ between 1986 to 2011, four times more than than the Canadian consumer price index over the same period (Kyrillidou, 2012; Statistics Canada, 2020). This was topped by another $55.89 \%$ increase between 2011 and 2016 (Haigh, 2016). In some universities, journal subscriptions consume up to $90 \%$ of the total library budget allocated to journal subscriptions (Laval University Library, 2019). This 
unsustainable financial situation has led several universities to cancel journal subscriptions (Laval University Library, 2019, University of Montreal Libraries, 2019, SPARC, 2020). In 2016, CRKN launched a national evaluation of journal usage in universities to help libraries assess the state of their collection and either cancel the big deals or negotiate better prices with publishers.

\section{Article Processing Charges}

Open Access is a movement aiming to make research output freely available on the internet by removing barriers to access such as subscription prices (Budapest Open Access Initiative, 2002). Two main models of open access were initially proposed by the Budapest initiative (BOAI): the first one, self-archiving (also known as green open access), allows researchers to deposit their already published articles in open electronic archives also known as repositories. The second one, also known as gold open access, relies on a brand new type of journal that makes new scientific articles immediately available on its website, with no copyright restriction. These new journals would not charge for subscription or access fees. While the original BOAI declaration suggested that these new journals find alternative sources of revenue (such as grants or adds-on that could be sold as an extra), article processing charges (APCs), a publishing fee charged to authors, emerged as one of the main sources of funding for OA journals.

While journal subscription cost is often seen by academic libraries as the elephant in the room, it appears little attention is given to APCs, which are an additional cost for journal access hidden in plain sight. APC unconsciously eats deep into the universities' funds that should have been spent on other important scholarship purposes are invested in APC. These article processing charges have led to the creation of a new "hybrid" open access model. This model had originally been proposed as a way for closed-access journals to transition to a fully open access model (Björk, 2012) but has evolved into a way for publishers to further maximize their profits. This model gets most of its revenues from subscriptions, but also allows authors to pay APC to make their paper available in OA, essentially getting paid twice for a single article, a practice also known as "doubledipping". Despite these articles already being financed by subscription fees, the average APC for hybrid articles remains very high, with an average price of around \$2,900 (USD; Jahn \& Tullney, 2016; Open APC, 2020; Solomon \& Björk, 2016) that may go as high as \$11,500 (USD; Springer Nature Group, 2020).

\section{Objective of the study}

By combining data on journals subscription expenditures of the Canadian Association of Research Libraries (CARL) member universities and estimated APCs paid by researchers affiliated to these universities, this study examines recent trends in the financial burden that this dual scholarly publishing market (subscriptions and APCs) imposes on Canadian universities.

\section{Data and Methods}

The journal and database subscriptions of the 29 CARL member libraries included in this study are licensed through the Canadian Research Knowledge Network consortium. The journal and database subscription cost datasets for 2016-2017 (Khair, 2018), 2017-2018 (Wilkinson, 2019a) 
and 2018-2019 (Wilkinson, 2019b) were made available through Canada's Federated Research Data Repository (FRDR).

We collected all articles and reviews published between 2015 and 2019 data for the 29 universities from Clarivate Analytics' Web of Science (WoS). Then we used the DOIs to obtain the OA status (gold, green, hybrid, bronze, closed) of each publication April 2020 Unpaywall data dump. We use only the gold and hybrid articles as these are the OA models that typically require the authors to pay APCs. We obtained the APCs for journals published by Elsevier, Wiley, Sage, and Taylor \& Francis from Matthias (2020). This dataset includes the open-access model and the APCs for each year. The amount of APCs paid is obtained by calculating the product of the number of articles published in gold or hybrid OA and the APCs charged by the journal. To avoid counting the same APCs twice due to inter-institutional collaboration, in this preliminary analysis we assume that the corresponding authors paid the APCs, and thus attribute the cost to that author's university.

\section{Results}

Figure 1 shows the evolution of gold and hybrid APCs paid to Elsevier, Sage, Taylor \& Francis and Wiley by Canadian universities from 2015 to 2019. Over these five years, the amount of APCs paid to these publishers has been steadily increasing from 2.2 million dollars (USD) in 2015 to 3.2 million in 2019. In total, over 14 million dollars in APCs have been paid with nearly two thirds for hybrid open access journals, which represents a considerable amount in "double-dipping".

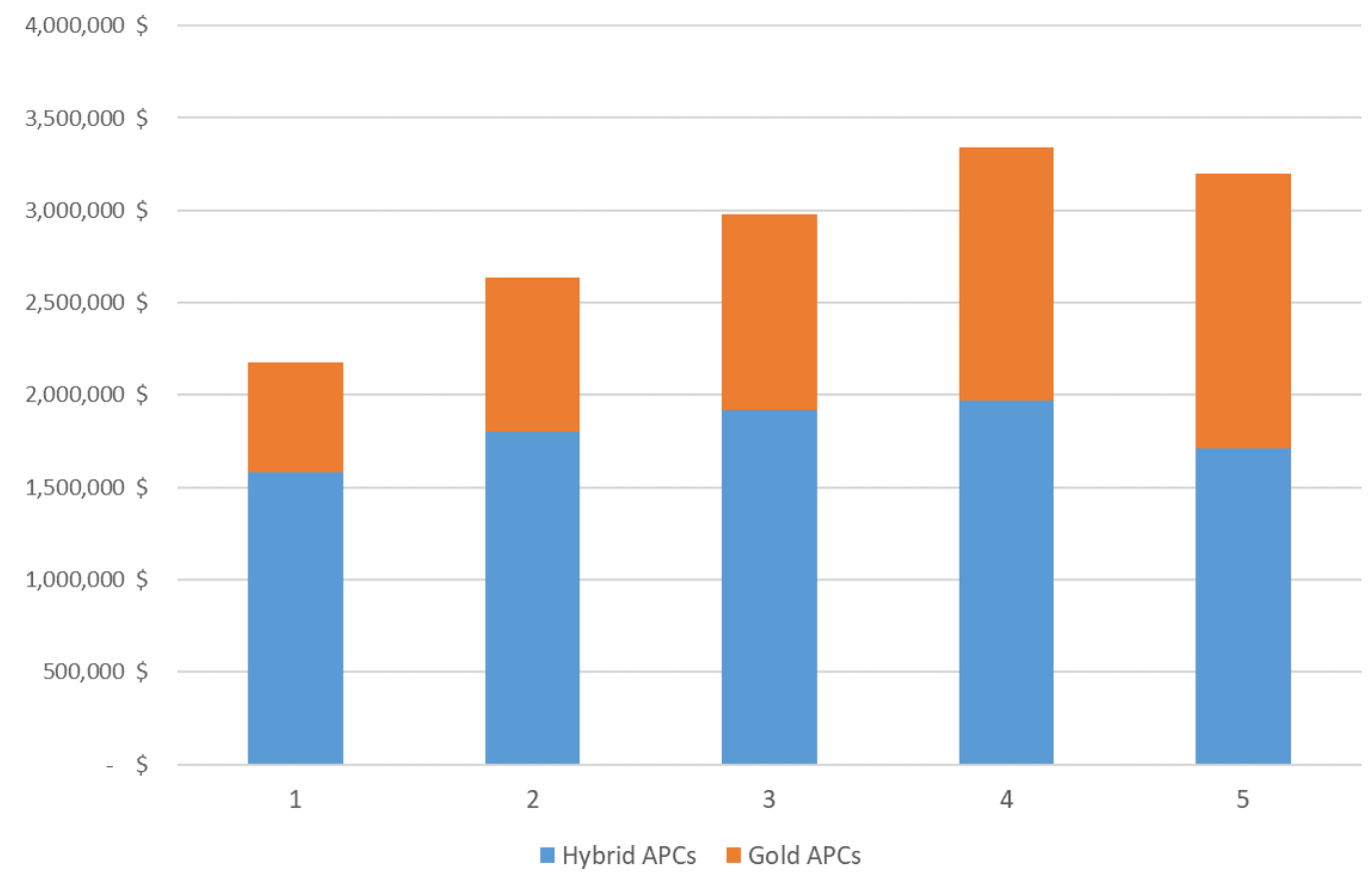

Figure 1. Share of hybrid and gold APCs paid by Canadian universities between 2015 and 2019 for Elsevier, Sage, Taylor \& Francis, and Wiley journals. 
Figure 2 shows the total amount of money spent by Canadian universities in subscription fees and APCs between the years 2015 and 2019 for Elsevier, Sage, Taylor \& Francis and Wiley journals. Over these five years, over 295.5 million dollars (USD) have been invested in scientific publishing, including 279.4 million in subscription fees with APCs representing roughly $5.7 \%$ of the total amount spent.

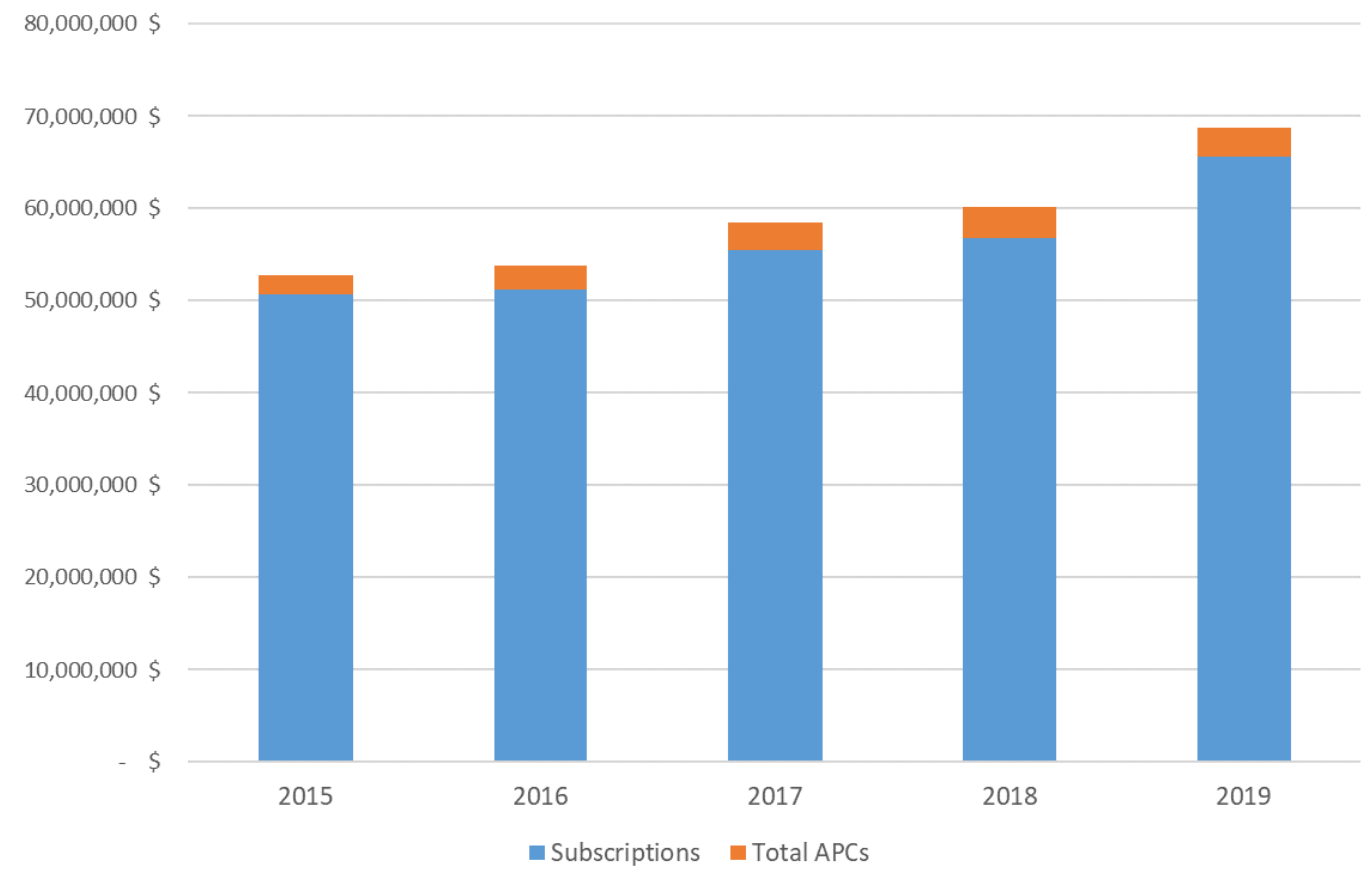

Figure 2. Share of subscriptions and APCs paid by Canadian universities between 2015 and 2019 for Elsevier, Sage, Taylor \& Francis, and Wiley journals.

Figure 3 shows the total subscription prices and APCs paid by Canadian universities between 2015 and 2019 for Elsevier, Sage, Taylor \& Francis, and Wiley journals. These results show a considerable variation between universities, bigger universities such as the University of Toronto paying considerably more in both subscriptions fees than smaller ones such as the Memorial University of Newfoundland. The total amount of APCs paid by researchers affiliated to Canadian universities also varies considerably, with the bigger universities spending much larger sums on APCs than smaller ones. 


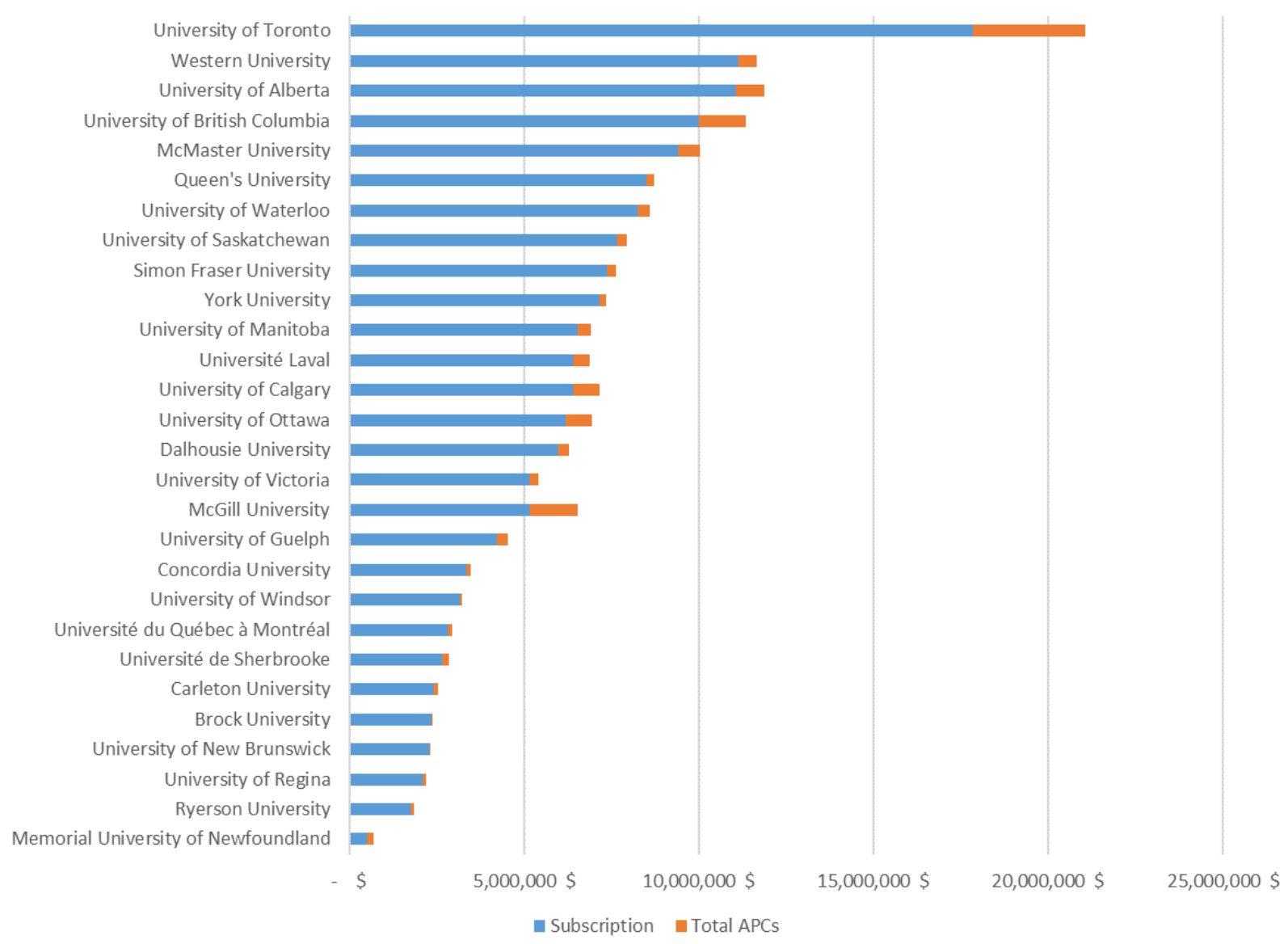

Figure 3. Total subscription prices paid by Canadian universities between 2015 and 2019 for Elsevier, Sage, Taylor \& Francis, and Wiley journals.

\section{Discussion}

Overall, the results indicate that the sum paid for access to scholarly journals in Canadian universities has been continuously and largely increasing over the last five years. Not only is this increase occurring despite recent efforts to reduce subscription fees, and despite the increasing adoption of $\mathrm{OA}$ as a business model for publishers, which in principle would come with a reduction of subscription fees for universities. Instead, OA under the APC regime appears to be adding a financial burden on Canadian higher education.

\section{Reference List:}

Brock, W.H. (1980). The Development of Commercial Science Journals in Victorian Britain," in ed. A.J. Meadows Development of Science Publishing in Europe. Amsterdam: Elsevier Science Publisher.

Edwards, R., \& Shulenburger, D. (2003). The High Cost of Scholarly Journals: (And What To Do About It). Change: The Magazine of Higher Learning, 35(6), 10-19. https://doi.org/10.1080/00091380309604123 
Federated Research Data Repository / dépôt fédéré de données de recherche. https://www.frdrdfdr.ca/repo/dataset/1e69652a-be35-d864-a866-df8383fcbca7

Frazier, K. (2001). The Librarians' Dilemma : Contemplating the Costs of the « Big Deal ». DLib Magazine. https://doi.org/10.1045/march2001-frazier

Haigh, S. (2016). Falling Canadian dollar raises longstanding issue of journal costs. Canadian Association of Research Libraries. https://www.carl-abrc.ca/news/journal-costs/?cnreloaded $=1$

Khair, S. A. (2018). Expenditures of CARL member libraries for scholarly resource subscriptions licensed through CRKN for 2016-2017 / Dépenses des bibliothèques membres de l'ABRC pour les abonnements aux ressources savantes sous licence $d u$ RCDR pour l'année 2016-2017.

Kyrillidou, M. (2012). Research Library Trends : A Historical Picture of Services, Resources, and Spending. Research Library Issues, 280, 20-27. https://doi.org/10.29242/rli.280.4

University Laval Library. (2019). Projets spéciaux - Opération de rationalisation des périodiques scientifiques. Retrieved from: https://www.bibl.ulaval.ca/rationalisationperiodiques-scientifiques

University of Montreal Libraries. (2019). Nouvelle ère pour les collections : Consultation UdeM. Retrieved from: https://bib.umontreal.ca/communications/grands-dossiers/collections$\underline{\text { nouvelle-ere\#c124710. }}$

SPARC. (2020). Big Deal Cancellation Tracking. Retrieved from: https://sparcopen.org/ourwork/big-deal-cancellation-tracking/

Shu, F., Mongeon, P., Haustein, S., Siler, K., Alperin, J. P., \& Larivière, V. (2018). Is It Such a Big Deal? On the Cost of Journal Use in the Digital Era | Shu | College \& Research Libraries. College and Research Libraries, 79(6), 785-798. https://doi.org/10.5860/crl.79.6.785

Suber, P. (2012). Open Access. The MIT Press.

Statistics Canada. (2020). Consumer Price Index, annual average, not seasonally adjusted [Data set]. Government of Canada. https://doi.org/10.25318/1810000501-ENG

Wilkinson, S. (2019a). Expenditures of CARL member libraries for scholarly resource subscriptions licensed through CRKN for 2017-2018 / Dépenses des bibliothèques membres de l'ABRC pour les abonnements aux ressources savantes sous licence du RCDR pour l'année 2017-2018. Federated Research Data Repository / dépôt fédéré de données de recherche. https://www.frdr-dfdr.ca/repo/dataset/a6567289-d82c-0569-73aff625658d6645

Wilkinson, S. (2019b). Expenditures of CARL member libraries for scholarly resource subscriptions licensed through CRKN for 2018-2019/Dépenses des bibliothèques 
membres de l'ABRC pour les abonnements aux ressources savantes sous licence du RCDR pour l'année 2018 - 2019. Federated Research Data Repository / dépôt fédéré de données de recherche. https://www.frdr-dfdr.ca/repo/dataset/a9f50f6a-4adb-2164-32ee$\underline{\text { f8702d26e98a }}$

Canadian Research Knowledge Network - Réseau canadian de documentation pour la recherche. (2018). Journal Usage Project. Retrieved from: https://www.crkn-rcdr.ca/en/journalusage-project 